\title{
Dynamic safety assessment of natural gas stations using Bayesian Network
}

\author{
Esmaeil Zarei ${ }^{\text {a }}$, Ali Azadeh ${ }^{\mathrm{b}}$ Nima Khakzad $^{\mathrm{c}}$, Iraj Mohammadfam ${ }^{\mathrm{a}, *}$ \\ ${ }^{a}$ Center of Excellence for Occupational Health Engineering, Research Center for Health Sciences, Faculty \\ of Health, Hamadan University of Medical Sciences, Hamadan, Iran. \\ ${ }^{\mathrm{b}}$ School of Industrial and Systems Engineering, Center of Excellence for Intelligent-Based Experimental \\ Mechanic, College of Engineering, University of Tehran, Iran. \\ ${ }^{\mathrm{c}}$ Safety and Security Science Section, Delft University of Technology, Delft, The Netherlands. \\ * Corresponding author: (I.Mohammadfam), \\ E-mail: mohammadfam@umsha.ac.ir, smlzarei65@gmail.com, Tel.: +98 811 8255963; fax: +98 811 \\ 8255301.
}




\begin{abstract}
Pipelines are one of the most popular and effective ways of transporting hazardous materials, especially natural gas. However, the rapid development of gas pipelines and stations in urban areas has introduced a serious threat to public safety and assets. Although different methods have been developed for risk analysis of gas transportation systems, a comprehensive methodology for risk analysis is still lacking, especially in natural gas stations. The present work is aimed at developing a dynamic and comprehensive quantitative risk analysis (DCQRA) approach for accident scenario and risk modeling of natural gas stations. In this approach, a FMEA is used for hazard analysis while a Bow-tie diagram and Bayesian network are employed to model the worst-case accident scenario and to assess the risks. The results have indicated that the failure of the regulator system was the worst-case accident scenario with the human error as the most contributing factor. Thus, in risk management plan of natural gas stations, priority should be given to the most probable root events and main contribution factors, which have identified in the present study, in order to reduce the occurrence probability of the accident scenarios and thus alleviate the risks.
\end{abstract}

Keywords: Dynamic risk analysis; Bayesian network; Bow-tie approach; City gate station; FMEA. 


\section{Introduction}

Pipelines are one of the most convenient and effective ways to transport enormous amounts of hazardous materials, especially natural gas $(\mathrm{NG})[1,2]$. In addition, NG consumptions and subsequently the pipeline systems are ever increasing worldwide [3, 4]. Due to the proximity and/or presence of natural gas transportation systems (NGTS), especially city gate stations (CGSs), to/in urban areas, the consequences of any damage (accidental or intentional) to the system can be disastrous. Therefore, the public safety and well-being largely depend on the safe operation of NGTS [1].

Specific characteristics of natural gas (high flammability, explosibility, and dispersion) have caused the accidents occurring in the NGTS to be different from other industrial accidents [5]. For examples, an explosion in a NG factory in Belgium in 2004 left 14 fatalities and more than 200 injuries [5]; conflagration of NG in Paraguay in 2004 caused more than 250 deaths, and in 2009, an explosion caused by NG leakage led to the largest conflagration in Moscow ever since the Second World War [5]. In 2010, a gas pipeline explosion in Sarakhs, Northeast of Iran, left 19 casualties and more than 30 severe injuries, and recently on 17 June 2016, an underground gas pipeline fire and explosion in Tehran, Iran, caused 2 fatalities and significant damage to surrounding residential buildings [6]. Statistics show a significant increase in the failure rate of NG pipeline in the last two decades [7]. Thus, it is very important to assess the risk of NGTS facilities.

One of the important facilities in the NGTS is CGS, where one or more of which is located in the entrances of a city. CGS performs several important operations: measuring the gas flow, reducing the pressure of gas by means of pressure regulators (from 500-1400 psig to $0.25-300$ psig), and adding odorant to the gas for safety purposes. CGS has a key role in timely and safe supply of NG where to residential, commercial and industrial customers.

NG is very flammable and explosive, and an accidental or intentional release of gas from the station facilities could pose catastrophic consequences to people, the environment, and the assets $[8,9]$. This issue becomes extremely dangerous to stations adjacent to densely populated areas. Thus, CGS accidents are threatening the urban safety and have become an important and controversial issue as for the general public $[7,10]$.

Therefore, it's important to assess and analyze the risk of the CGS operations in order to provide a safe condition and to protect the human lives and the properties [5]. Risk analysis can provide 
authorities with a useful tool for specifying high-risk equipment and developing risk-based preventive and mitigative strategies $[9,11,12]$.

Quantitative risk analysis (QRA) plays an important role in effective controlling of safety risks in hazardous materials transportation systems and has been employed as an efficient tool by regulatory authorities to successfully improve safety levels in gas facilities instead of applying prescriptive (giving exact rules and instructions) approaches [13].

Several studies have been conducted to assess safety risks of NGTS [4, 5, 8, 11, 13-15]. Most of the previous studies, however, have merely focused on gas pipelines whereas the work devoted to other important components of NGTS such as gas stations has been very few. In addition to the limited scope of the previous work, most of the methods used for QRA in previous studies suffer from limitations such as being statistic, incapable of handling data scarcity and data uncertainties, and inability to consider dependencies [16-18].

Conventional QRA methods such as fault tree, event tree, and Bow-tie diagram cannot easily be employed to model dynamic risks and conditional dependencies, which are very important in the risk analysis of the chemical and process industries $[9,19,20]$. The static characteristic of conventional QRA methods causes the process variations which almost always occur during the operational time of a gas station to be ignored in the risk analysis. Also in the most of these methods, using generic failure probability data has introduced uncertainty to the analysis. Generic data is information from similar systems, available from databases or safety/accident reports. This information may be the only information available in the initial stages of system failure analysis or design regardless of possible differences arising from dissimilarities between the operational/environmental conditions of the system of interest and those under which the generic data has been provided [21]. The usage of such generic data can bring some uncertainty into analysis, also known as source-to-source uncertainty [22]. This type of uncertainty can be diminished as more case-specific data is used to update the probabilities [19, 20, 22, 23]. Therefore, to overcome these disadvantages, a dynamic and comprehensive quantitative risk analysis (DCQRA) approach will be applied in the present work based on Bayesian network.

The present study is aimed at showing the importance of a dynamic and comprehensive approach in accident scenario modeling and risk analysis of natural gas stations. In this approach, FMEA (failure mode and effect analysis) is used for hazard analysis and determining the worst case accident scenarios. Bow-tie diagram is applied to cause-consequence analysis of the worst case 
accident scenario while Bayesian network technique is employed to consider conditional dependencies and risk updating.

Section 2 explains the methods used in this work; Section 3 provides main results of the work and their discussion; Section 4 is devoted to the conclusions.

\section{Material and Method}

In order to introduce the methodology of the work, this section provides a brief overview of DCQRA approach as shown in Fig.1.

Fig. 1. Overview of the procedure used for DCQRA

\subsection{Hazard Analysis}

\subsubsection{FMEA}

The failure mode and effects analysis (FMEA) technique is a valuable qualitative and quantitative analysis method used for the evaluation of potential failure modes and their effect(s) on a system. It is primarily a reliability tool to identify failure modes that would adversely affect overall system reliability. FMEA is a structured, systematic and inductive reasoning (forward logic) technique to include failure rates of each failure mode in order to achieve a quantitative probabilistic analysis. Additionally, the FMEA can be extended to evaluate failure modes that may result in an undesired system state, such as a system hazard, and thus can be used for hazard analysis. When component failure rates are attached to the identified potential failure modes, a failure probability of subsystem or component can be derived. Severity and probability evaluation of failure modes provide a prioritized list of corrective actions. FMEA can also be extended to identify hazards resulting from potential failure modes and evaluating the resulting mishap risk. Successful development of an FMEA requires that the analyst includes all significant failure modes for each contributing element or part in the system [15, 24].

The information needed for FMEA is the task description, failure modes, failure causes, failure effects on the system, the severity of effects $(S)$, the probability of failure $(P)$, the detection level (D), and the risk priority number (RPN). RPN is calculated as:

$R P N=S \times P \times D$ 
$\mathrm{D}$ indicates the probability that the event not being detected before the user notices it. We use seven scores to determine the severity of failures as $S=(1,2, . ., 7)$ in which 1 refers to having no effects while 7 refers to catastrophic effects ${ }^{1}$. As for the failure probability and the likelihood of detection, similar scores can be employed as $\mathrm{P}=(1,2, . ., 7)^{2}$ and $\mathrm{D}=(1,2, . ., 7)^{3}$.

\subsubsection{Bow-tie approach (Accident scenario modeling)}

BT is one the best graphical approaches to model an accident scenario, starting with the causes and ending to the consequences of the accident scenario. BT is composed of a fault tree (FT) on the left-hand side to represent basic events leading to a top event (located in the center of BT) and an event tree (ET) on the right-hand side to investigate possible consequences resulted from the top event considering the operational failure of safety barriers [19]. BT provides an accident scenario with qualitative and quantitative modeling. In the qualitative view, BT provides a clear representation of the logical relationships among basic and intermediated events leading to a top event and how the failure of safety barriers can escalate the top event to accident consequences. In the BT, the quantitative evaluation of the FT part requires the failure and/or occurrence probability of the basic events. Given these data, there are several methods to evaluate the

probability of the top event, such as the method of minimum cut sets, the gate-by-gate method, and Monte Carlo simulation [24].

The ET is constructed from the initial event, which is the top event of the FT, and is divided to two branches at each safety barrier where one branch refers to the operation of the safety barrier while the other branch for the failure of the safety barrier. Each branch represents a different sequence of events and terminates in a consequence. The occurrence probability of each consequence is calculated based on the failure (or success) probability of safety barriers that are placed on each branch.

\subsubsection{Bayesian Network}

\footnotetext{
11: no effect; 2: negligible; 3: low; 4: moderate; 5: high; 6: critical; 7: catastrophic.

${ }^{2}$ 1: never; 2 : possible; 3 : low; 4: moderate; 5 : high; 6: very high; 7 : certain.

${ }^{3} 1$ : certain; 2 : very high; 3 : high; 4 : moderate; 5 : low; 6: negligible; 7 : never.
} 
A Bayesian network $(\mathrm{BN})$ is a probabilistic graphical model that represents a set of random variables and their conditional dependencies via a directed acyclic graph [25]. Nodes represent variables, which could be the components of a system, while edges represent conditional dependencies between the connected nodes. Each node is associated with a probability distribution as a function of the states of the node's parent variables ${ }^{4}$. Due to its flexible structure and probabilistic reasoning engine, $\mathrm{BN}$ is a popular method for modeling and risk analysis of large and complex systems. To take into view the conditional dependencies of variables, BN demonstrates the joint probability distribution of a set of variables $U=\left\{X_{1}, \ldots, X_{n}\right\}$ as $[25,26]$ :

$P(U)=\prod_{i=1}^{n} P\left(X_{i} \mid P_{a}\left(X_{i}\right)\right)$

Where $P_{a}\left(X_{i}\right)$ is the parent set of variable $\mathrm{X}_{\mathrm{i}}$. According to this, the probability of $\mathrm{X}_{\mathrm{i}}$ is calculated as:

$P\left(X_{i}\right)=\sum_{U \backslash X_{i}} P(U)$

$\mathrm{BN}$ makes use of Bayes theorem in order to update the prior probability of events given new information, called evidence E, yielding the posteriors as Equation (4). This evidence can be in the form of the occurrence of near misses, mishaps, incidents, or the observation of the consequences of the accident that become available during the lifecycle of a process.

$P(U \mid E)=\frac{P(U, E)}{P(E)}=\frac{P(U, E)}{\sum_{U} P(U, E)}$

\subsection{CGS description}

The natural gas for the most distribution systems is received from transmission pipelines and fed through one or more CGSs. The basic function of these stations is to measure the gas flow with metering devices and reduce its pressure (from approximately 500-1,400 psig to about 0.25-300 psig) by means of pressure regulators. Gas received at the station may or may not contain odorant (Mercaptan), the compound that gives odorless natural gas its distinctive smell. Odorant

\footnotetext{
${ }^{4}$ In Bayesian network, a node from which an edge is directed to another node is called parent while the other node to which the edge is directed is called child.
} 
must be added to the gas if it is received with insufficient or no odorant before the gas can leave the station. A typical CGS is composed of a complex array of valves, filters, pipes, and pressure reduction devices (regulators) designed to meter the gas and reduce its pressure so that it can be delivered safely to customers through distribution networks consisting of local gas mains, smaller-diameter service lines, and individual customer meters. Figure 2 shows the location of CGS in NG industry while a typical CGS and its main parts have been schematized in Figure 3.

Fig. 2. Natural gas industry and CGS location

[Honeywell International, Inc.: www.slideshare.net]

Fig.3.Main parts of each pipeline in a typical CGS

[http://www.icggroup.com/Pages/Gas-Pressure-Reducing-Stations.aspx]

\section{Results and Discussion:}

\subsection{FMEA}

We have performed a FMEA (i) to identify all hazard sources in CGS plants, (ii) to provide a complete qualitative perspective of the hazard sources by considering their function, failure modes, failure causes and failure effects on the plant, and (iii) to establish a quantitative hazard analysis by assigning a degree of severity, probability, and detection level to each hazard source in order to obtain risk priority number for each hazard. It should be noted that the values of S, P, and D for each component's failure modes and effects have been decided by a group of safety and process experts in the field. Fig. 4. provides RPN for all the hazard sources in the CGS of interest. To this end, first the RPNs of all failure modes are estimated for each piece of equipment, and then the largest is chosen as the equipment RPN.

As it can be seen, the regulator system of the CGS has the highest RPN and according to this, we consider its failures the worst case accident scenario to be included in a comprehensive and detailed risk analysis in the present study. Table 1 exemplifies the FMEA of the regulator system in CGS as the worst case accident scenario (the highest RPN).

Table 1. Failure mode and effects analysis of regulator system in CGS 
Fig.4. RPN of all hazard sources (hazardous subsystems) on CGS plants.

\subsection{Bow-tie diagram modeling}

Fig. 5 shows an accident scenario modeling for the worst case accident scenario using BT approach, with the regulator system failure as the central event (top event of the FT). To develop the BT, several meetings were conducted to interview academicians, safety, process and instrumentation engineers, and operators who are working in CGS plants in order to identify the main factors contributing to the failure of the regulator system. The results pinpointed the three main contributors, including human errors (unsafe behaviors), process failures, and mechanical failures. These main factors were further broken down to basic and intermediate events as depicted in Fig.5. Symbols, descriptions, and the failure probabilities of the basic events are presented in Table 2. The symbols $X$ and IE indicate the basic and intermediate events, respectively (Tables 2 and 3). In this research, for mechanical and electrical components, some probabilities were obtained from databases such as ORDEA, and some from literature. However, where such specific failure probability data was lacking, for example in case of human failures, failure probabilities were estimated by field experts during safety meetings [27, 28].

Fig. 5- Accident scenario modeling of regulator system failure using Bow-tie approach

Table 3 shows symbols and descriptions of intermediate events and safety barriers of the BT. As

can be seen from Figure 5, automatic emergency shutdown $\left(\mathrm{ESD}_{\mathrm{a}}\right)$, manual emergency shut down $\left(\mathrm{ESD}_{\mathrm{m}}\right)$, immediate ignition (II), delayed ignition (DI), and the presence/absence of congestion (Cong) [3] have been considered as safety barriers the failure or success of which can lead to nine consequences (Table 4).

Table 3. Intermediate events and safety barriers of the BT in Fig. 5. 
Table 4 reports the possible consequences of the regulator system failure, including near miss, flash fire, VCE, etc. Among the safety barriers, the activation of $\mathrm{ESD}_{\mathrm{m}}$ largely depends on the notification of the gas leakage by residents in the vicinity of the gas station or passersby and reporting to the national gas company. After receiving a leakage report, technical workers of the company will attend on the gas station and take action to close the $\mathrm{ESD}_{\mathrm{m}}$ valve. Thus, the severity of the consequences (e.g., material loss rate, property damage, and the duration of fire) presented in Table 4 to a large extent depends on the time delay before closing ESD $_{\mathrm{m}}$.

Table 4. Consequences of the regulator system failure.

Table 5. Failure probability of safety barriers in BT [27]

Table 5 shows failure probability of safety barriers [27]. It is worth noting that the probability of a delayed ignition increases with the increase in the dimension of the gas vapor cloud and thus the volume of the released gas. Since the failure of $\mathrm{ESD}_{\mathrm{m}}$ will normally cause a larger amount of gas to release, the possibility of a delayed ignition will be higher accordingly (Table 5).

\subsection{Bayesian Network modeling}

Although BT is one of the best and popular method in risk analysis, however, it has the disadvantage of being static and cannot adapt itself to the dynamics of accidents. To relax these limitations, we used a $\mathrm{BN}$ in order to provide a dynamic risk analysis. BN can take into account new information such as near misses and mishaps which is prevailing in the process industry to update the risks $[19,20]$. We used an algorithm for mapping BT to BN proposed by Khakzad et.al, [20].

Fig. 6. Dynamic cause-consequence analysis of the regulator system failure using BN

Fig. 6 illustrates the developed BN. As previously mentioned, the probability of a delayed ignition depends on the volume of the released gas; as a result, in the BN of Figure 6 the node $\mathrm{ESD}_{\mathrm{m}}$ is connected to DI. Allocating the probabilities in Tables 2 and 5 to the basic events and 
the safety barriers, the probabilities of the top event, its main contributing factors and the consequences are calculated and presented in Table 6 using both $\mathrm{BT}$ and $\mathrm{BN}^{5}$ approaches.

One of the strengths of both the BT and the BN is deductive reasoning to predict the probabilities of the scenario occurrence and its consequences [29]. Table 6 shows the results of the predictive analysis of the regulator system failure. It is worth noting that all the probability values calculated using the $\mathrm{BN}$ are slightly different than those of the BT. This is due to the consideration of conditional dependency among root events (basic events) in the form of common failure causes in the BN, which cannot be considered in the BT [30]. This is more significant for the mechanical failure probability, due to the dependency of $\mathrm{IE}_{12}$ and $\mathrm{IE}_{13}$ because of $\mathrm{X}_{21}$, and the dependency of $\mathrm{IE}_{14}$ and $\mathrm{IE}_{17}$ because of $\mathrm{X}_{33}$ (Fig.6).

Deductive reasoning is one of the unique and specific features of $\mathrm{BN}$ that is of great value in dynamic risk analysis for updating the probability of primary events given accident precursors $[29,31]$. This type of reasoning also leads to the innate ability of $\mathrm{BN}$ in uncertainty reduction while updating the prior beliefs and generic probabilities, a key modeling aspect in dynamic safety risk analysis of process systems. Repetitive replacement of posteriors instead of priors in re-analysis of the accident scenario leads to a continuous decrease of uncertainty and also provides a real-time and up-to-date accident scenario analysis [31]. Table 6 (3rd column) shows a deductive reasoning for the probability updating given the failure of the regulator system (i.e., $\left(\mathrm{P}\left(x_{i} \mid R S=\right.\right.$ failed $\left.)\right)$ for the main risk contributors and the potential consequences. In this case, the probability of human failures has significantly increased from 6.08E-02 to 8.54E-01 (the ratio of variation $(\mathrm{RoV})=13.05)$, implying the most contribution factor $(\mathrm{MCF})$ to the regulator system failure. This, in turn, emphasizes the critical role of human error among the others in the failure of the regulator system. This is in agreement with studies that have highlighted the role of human error in $70 \%$ to $90 \%$ of accidents in the chemical and process industries [32-34]. The most probable consequences also are $\mathrm{C} 1$ and $\mathrm{C} 2$ with occurrence probabilities of 0.67 and 0.14 , respectively. This is mainly due to the successful operation of the emergency shutdown valves, i.e., $\mathrm{ESD}_{\mathrm{a}}$ and $\mathrm{ESD}_{\mathrm{m}}$, in release controlling of natural gas when regulator system is failed. As can be noted from the results, in the natural gas station under study, the safety barriers are able to considerably mitigate the consequences of the accident scenario.

\footnotetext{
${ }^{5}$ The BN was simulated and run in software GeNIe 2.0 (http://www.bayesfusion.com).
} 
Table 6. Probabilities calculated from BT and BN.

A comparison of the prior and posterior (updated) probabilities of the basic events is depicted in Fig. 7(a) while in Fig. 7(b) the ratio of variation (RoV) in the probabilities is shown. For a basic event, the RoV can be calculated as:

$\operatorname{RoV}\left(X_{i}\right)=\frac{\pi\left(X_{i}\right)-\theta\left(X_{i}\right)}{\theta\left(X_{i}\right)}$

Where $\pi\left(X_{i}\right)$ and $\theta\left(X_{i}\right)$ denote, respectively, the posterior and prior probabilities of $X_{i}$.

As can be seen, $\mathrm{X}_{1-}-\mathrm{X}_{14}$ and $\mathrm{X}_{20}-\mathrm{X}_{29}$ show the highest RoV, indicating the most critical basic events contributing to the failure of the regulator system in CGS. Comparing Figs. 7(a) and 7(b), it can be noticed that relying on merely prior probabilities or posterior probabilities to identify critical events is very likely to lead to inaccurate results.

(a)

(b)

Fig 7. (a) Comparison of the prior and posterior (updated) probabilities of basic events. (b) Ratio of variation of the probabilities.

Risk importance measures such as Birnbaum Importance Measure (BIM), Risk Achievement Worth (RAW), and Risk Reduction Worth (RRW) are widely used in probabilistic safety analyses for ranking of basic events based on their contribution to the failure of the system [35, 36]. In the present study, to validate the applicability of RoV in the identification of critical basic events, BIM is used to identify and rank order the most critical basic events leading to the failure of the regulator system. This approach is well known in classical sensitivity analysis [35]. Using the BN developed in Fig. 6, the BIM of the basic events can readily be calculated, by setting each basic event to its states, one at a time, and calculating the conditional failure probability of the regulator system. Having the conditional failure probability of the regulator system (RS) given the functioning and malfunctioning of the basic event $\mathrm{X}_{\mathrm{i}}$, the BIM of $\mathrm{X}_{\mathrm{i}}$ can be calculated using Eq. (6): 


$$
\operatorname{BIM}\left(X_{i}\right)=P\left(R S=\text { fail } \mid X_{i}=\text { fail }\right)-P\left(R S=\text { fail } \mid X_{i}=\text { work }\right)
$$

Fig. 8. BIM of the basic events.

As can be seen from Fig.8, the results obtained from BIM analysis is in agreement with those obtained from RoV analysis, demonstrating that RoV can be used as a reliable measure of importance in system failure analysis.

Using the RoV, the smallest combinations of events that are necessary and sufficient to cause a system failure - also known as minimal cut set (MCS) - can be ranked based on their criticality. As such, in risk management plans under limited resources (time, budget, staff, etc.), the priority can be given to the most critical MCSs in order to reduce the failure probability of the regulator system and thus alleviate the risk in the CGS plant.

Considering a MCS comprising a number of basic events, the RoV of the MCS can be calculated similar to that of a basic event as:

$\operatorname{RoV}(M C S)=\frac{\prod_{i \in M C S} \pi\left(X_{i}\right)-\prod_{i \in M C S} \theta\left(X_{i}\right)}{\prod_{i \in M C S} \theta\left(X_{i}\right)}$

As can be seen, the same critical basic events which were identified in Fig. 7(b) have been identified as the most critical MCSs in Fig. 9.

Fig 9. Ratio of variation for the MCSs of regulator systems failure.

\section{Conclusion}

The present study has illustrated an application of Bayesian network to a comprehensive and dynamic safety risk modeling of natural gas stations. The application of the approach provides a risk-based investigation to identify the risk level of all equipment in the station. Accordingly, the regulator system failure of the station has been identified as the critical equipment in the station. Performing an accident cause-consequence analysis using Bow-tie diagram, the basic events, 
intermediate events, safety barriers, and the potential consequences of the regulator system failure were identified. The developed Bow-tie was converted to a Bayesian network to capture dependencies and perform probability updating. Human errors turned to be the most contributing factor to the regulator system failure. Among the potential consequences, material loss has been identified as the most probable consequence. The results of the study show that the identification of critical basic events should be carried out based on the ratio of variation of probabilities instead of merely focusing on prior or posterior probabilities.

\section{Acknowledgments}

The first and the last authors gratefully acknowledge the financial support provided by Hamadan University of Medical Science (Grant No: 9412117050) and Iranian National Science Foundation. 


\section{References:}

[1] F.A. Batzias, C.G. Siontorou, P.M.P. Spanidis, Designing a reliable leak bio-detection system for natural gas pipelines, J. Hazard. Mater. $186(2011) 35-58$.

[2] G.A. Papadakis, Assessment of requirements on safety management systems in EU regulations for the control of major hazard pipelines, J. Hazard. Mater.78 (2000) 63-89.

[3] J.G. Ramírez-Camacho, F. Carbone, E. Pastor, R. Bubbico, J. Casal, Assessing the consequences of pipeline accidents to support landuse planning.Safety Sci. http://dx.doi.org/10.1016/j.ssci.2016.01.021, 2016 (In Press).

[4] C. Vianello, G. Maschio, Quantitative risk assessment of the Italian gas distribution network, J. Loss Prev. Proc.32 (2014) 5-17.

[5] Z.Y. Han, W.G. Weng, Comparison study on qualitative and quantitative risk assessment methods for urban natural gas pipeline network, J. Hazard. Mater.189 (2011) 509-518.

[6] http://www.bbc.com/news/world-middle-east-36563635 in, 2016 (accessed 31 Aguest 2016)

[7] H. Wang, I.J. Duncan, Understanding the nature of risks associated with onshore natural gas gathering pipelines, J. Loss Prev. Proc.29 (2014) 49-55.

[8] P. Russo, F. Parisi, Risk-targeted safety distance of reinforced concrete buildings from natural-gas transmission pipelines, Reliab. Eng. Syst. Saf. 148 (2016) 57-66.

[9] I. Mohammadfama, E. Zarei, Safety risk modeling and major accidents analysis of hydrogen and natural gas releases: A comprehensive risk analysis framework, Int. J. Hydrogen Energ. 40 (2015) 13653-13663.

[10] H. Wang, I.J. Duncan, Likelihood, causes, and consequences of focused leakage and rupture of U.S. natural gas transmission pipelines, J. Loss Prev. Proc.30 (2014) 177-187.

[11] A. Jamshidi, A. Yazdani-Chamzini, S.H. Yakhchali, S. Khaleghi, Developing a new fuzzy inference system for pipeline risk assessment, J. Loss Prev. Proc.26 (2013) 197-208.

[12] A. Dormohammadi, E. Zarei, M. Delkhosh, A. Gholami, Risk analysis by means of a QRA approach on a LPG cylinder filling installation, Process Saf. Prog. 33 (2014) 77-84.

[13] Y.-D. Jo, B.J. Ahn, A method of quantitative risk assessment for transmission pipeline carrying natural gas, J. Hazard. Mater.123 (2005) 1-12.

[14] Z.Y. Han, W.G. Weng, An integrated quantitative risk analysis method for natural gas pipeline network, J. Loss Prev. Proc.23 (2010) 428-436.

[15] F. Khosravirad, E. Zarei, I. Mohammadfam, E. Shoja, M.M. Daryani, Explosion risk analysis on Town Border Stations (TBS) of natural gas using Failure Mode \& Effect Analysis (FMEA) and Fault Tree Analyses (FTA) methods, Iran Occup Health. 12 (2016) 16-27.

[16] H.J. Pasman, S. Jung, K. Prem, W.J. Rogers, X. Yang, Is risk analysis a useful tool for improving process safety?, J. Loss Prev. Proc.22 (2009) 769-777.

[17] H. Pasman, W. Rogers, Bayesian networks make LOPA more effective, QRA more transparent and flexible and thus safety more definable!, J. Loss Prev. Proc.26 (2013) 434-442.

[18] M. Kalantarnia, F. Khan, K. Hawboldta, Dynamic risk assessment using failure assessment and Bayesian theory, J. Loss Prev. Process Ind. 22 (2009) 600-606.

[19] N. Khakzad, F. Khan, P. Amyotte, Dynamic risk analysis using bow-tie approach, Reliab. Eng. Syst. Saf.104 (2012) 36-44.

[20] N. Khakzad, F. Khan, P. Amyotte, Dynamic safety analysis of process systems by mapping bow-tie into Bayesian network, Process.

Saf. Environ. Prot. 91 (2013) 46-53.

[21] B.M. Ayyub, Risk Analysis in Engineering and Economics, CRC Press Company, Washington, D.C, 2003.

[22] Khakzad N, Khan F, Paltrinieri N. On the application of near accident data to risk analysis of major accident, Reliab. Eng. Syst. Saf. 126 (2014) 116-125.

[23] E. Zarei, M. Jafari, N. Badri, Risk assessment of vapor cloud explosions in a hydrogen production facility with consequence modeling, J. Res. Health. Sci. 13 (2013) 181-187.

[24] S. Mannan, Lees' Loss Prevention in the Process Industries, Hazard Identification, Assessment and Control, Third ed., Elsevier Inc, 2005 .

[25] Jensen FV, Nielsen TD, Bayesian Networks and Decision Graphs., 2nd edition., Springer, New York, 2007.

[26] J. Pearl, Probabilistic Reasoning in Intelligent Systems, Morgan Kaufmann,, , San Francisco, California, 1988.

[27] O. Participants, Offshore and Onshore Reliability Database handbook, Høvik, Det Norske Veritas (DNV), 2002.

[28] G.C. Qinglei Tan, Lei Zhang, Jianmin Fu, Zemin Li, Dynamic accident modeling for high-sulfur natural gas gathering station. Process. Saf. Environ. Prot.92 (2014) 565-576.

[29] Uffe B. Kjærulff, A.L. Madsen, Bayesian Networks and Influence Diagrams: A Guide to Construction and Analysis, Springer New York, 2013.

[30] Z. Yuan, N. Khakzad, F. Khan, P. Amyotte, Risk analysis of dust explosion scenarios using Bayesian networks, Risk anal. 35 (2015) 278-291.

[31] N. Khakzad, F. Khan, P. Amyotte, Safety analysis in process facilities: Comparison of fault tree and Bayesian network approaches, Reliab. Eng. Syst. Saf.96 (2011) 925-932.

[32] E. Zarei, I. Mohammadfam, M. Aliabadi, A. Jamshidi, F. Ghasemi, Efficiency prediction of control room operators based on human reliability analysis and dynamic decision-making style in the process industry, Process Saf. Prog. 33 (2016) 192-199.

[33] K.L. S.G. Kariuki, Integrating human factors into process hazard analysis, Reliab. Eng. Syst. Saf.92 (2007) $1764-1773$.

[34] J. Rena, I. Jenkinsona, J. Wanga, D.L. Xub, J.B. Yangb, A methodology to model causal relationships on offshore safety assessment focusing on human and organizational factors, J. Saf. Res. 39 (2008) 87-100.

[35] Aven T, Nøkland T.E, On the use of uncertainty importance measures in reliability and risk analysis, Reliab. Eng. Syst. Saf. 95 (2010) $127-133$.

[36] Z. Birnbaum, On the importance of different components in a multicomponents systemIn: Mulitivariate analysis-II,Krishnaiah PR, Academic Press, New York, 1969. 
Table 1. Failure mode and effects analysis of regulator system in CGS

\begin{tabular}{|c|c|c|c|c|c|c|c|}
\hline Task & Failure mode & Failure Causes & Failure Effect (on system) & $\mathrm{S}$ & $\mathrm{P}$ & $\mathrm{D}$ & RPN \\
\hline $\begin{array}{l}\text { To meter the } \\
\text { gas flow }\end{array}$ & Filter blocked/ clogged & Dirty gas & Decrease of feeding pressure & 3 & 5 & 1 & 15 \\
\hline $\begin{array}{l}\text { To reduce the } \\
\text { pressure of gas }\end{array}$ & Pilot cannot be closed & Sour gas & $\begin{array}{l}\text { Increase of motorization } \\
\text { pressure }\end{array}$ & 5 & 3 & 1 & 15 \\
\hline \multirow[t]{4}{*}{ To add odorant } & Pilot cannot control & Fabric quality & $\begin{array}{l}\text { Decrease of motorization } \\
\text { pressure }\end{array}$ & 5 & 4 & 1 & 20 \\
\hline & $\begin{array}{l}\text { Pilot cannot feed the } \\
\text { regulator }\end{array}$ & $\begin{array}{l}\text { Freezing and rupture of } \\
\text { the diaphragm }\end{array}$ & $\begin{array}{l}\text { Lack of balancing pressures } \\
\text { and charge or discharge of the } \\
\text { motorization pressure chamber }\end{array}$ & 5 & 4 & 1 & 20 \\
\hline & & Failures of seats/ & & & & & \\
\hline & Main diaphragm ruptures & $\begin{array}{l}\text { sensings/sleeves and } \\
\text { orifice }\end{array}$ & Downstream line breaks & 7 & 4 & 1 & 28 \\
\hline
\end{tabular}


Table 2. Description and failure probability of basic events

\begin{tabular}{|c|c|c|c|c|c|}
\hline Symbol & Description & Probability & Symbol & Description & Probability \\
\hline $\mathrm{X}_{1}$ & Wrong hazard assessment & $9.00 \mathrm{E}-04$ & $\mathrm{X}_{23}$ & Poor inspection program & $5.00 \mathrm{E}-05$ \\
\hline $\mathrm{X}_{2}$ & Intentional error during operation & $1.00 \mathrm{E}-04$ & $\mathrm{X}_{24}$ & Cathodic protection & $5.00 \mathrm{E}-04$ \\
\hline $\mathrm{X}_{3}$ & Inadequate training & 4.00E-04 & $\mathrm{X}_{25}$ & Flaws in sensing testing & $4.00 \mathrm{E}-05$ \\
\hline $\mathrm{X}_{4}$ & Inadequate experience & $1.00 \mathrm{E}-04$ & $\mathrm{X}_{26}$ & Closing gear to gear of pipes & $4.00 \mathrm{E}-05$ \\
\hline $\mathrm{X}_{5}$ & Station restart up & $8.00 \mathrm{E}-03$ & $\mathrm{X}_{27}$ & Poor detection of leakages & $4.00 \mathrm{E}-05$ \\
\hline $\mathrm{X}_{6}$ & Sudden interruption of gas subscribers & $8.00 \mathrm{E}-03$ & $\mathrm{X}_{28}$ & Failure of restraint of sensing & 4.00E-04 \\
\hline $\mathrm{X}_{7}$ & Fear of explosion and fire & $8.00 \mathrm{E}-03$ & $\mathrm{X}_{29}$ & Inappropriate fittings & 4.00E-05 \\
\hline $\mathrm{X}_{8}$ & Poor/lack of equipment & 8.00E-03 & $\mathrm{X}_{30}$ & High velocity gas & $2.00 \mathrm{E}-02$ \\
\hline $\mathrm{X}_{9}$ & Lack of permit implementation & $7.00 \mathrm{E}-03$ & $\mathrm{X}_{31}$ & Gas pressure drop & $2.50 \mathrm{E}-02$ \\
\hline $\mathrm{X}_{10}$ & Failure in permit implementation & 7.00E-03 & $\mathrm{X}_{32}$ & Small pipes diameter & $1.50 \mathrm{E}-02$ \\
\hline $\mathrm{X}_{11}$ & Wrong permit & $8.00 \mathrm{E}-03$ & $\mathrm{X}_{33}$ & High gas flow & $2.00 \mathrm{E}-02$ \\
\hline $\mathrm{X}_{12}$ & Without permit & 7.00E-03 & $\mathrm{X}_{34}$ & Ambient temperature changes & 4.00E-03 \\
\hline $\mathrm{X}_{13}$ & Not testing of ran along with sensing & $3.00 \mathrm{E}-03$ & $\mathrm{X}_{35}$ & Long distances to subscribers & $1.00 \mathrm{E}-02$ \\
\hline $\mathrm{X}_{14}$ & Tearing sleeve & $4.00 \mathrm{E}-03$ & $\mathrm{X}_{36}$ & Heather off & $1.50 \mathrm{E}-02$ \\
\hline $\mathrm{X}_{15}$ & Poor assembling & $3.00 \mathrm{E}-02$ & $\mathrm{X}_{37}$ & Poor set up in heater temperature & $1.50 \mathrm{E}-02$ \\
\hline $\mathrm{X}_{16}$ & Non-standard equipment & $2.50 \mathrm{E}-02$ & $\mathrm{X}_{38}$ & Tangential stress & $1.50 \mathrm{E}-01$ \\
\hline $\mathrm{X}_{17}$ & Poor maintenance & $5.00 \mathrm{E}-02$ & $\mathrm{X}_{39}$ & Shear stress & $1.50 \mathrm{E}-01$ \\
\hline $\mathrm{X}_{18}$ & Cold weather & $1.50 \mathrm{E}-02$ & $\mathrm{X}_{40}$ & Axial stress & $1.50 \mathrm{E}-01$ \\
\hline $\mathrm{X}_{19}$ & Weakness filtering & $1.30 \mathrm{E}-02$ & $\mathrm{X}_{41}$ & Tensile axial load & $2.00 \mathrm{E}-01$ \\
\hline $\mathrm{X}_{20}$ & Erosion & $5.00 \mathrm{E}-04$ & $\mathrm{X}_{42}$ & Compressive axial load & $2.00 \mathrm{E}-01$ \\
\hline $\mathrm{X}_{21}$ & Anti-corrosion layer & $1.00 \mathrm{E}-03$ & $\mathrm{X}_{43}$ & Vibration & $2.50 \mathrm{E}-01$ \\
\hline $\mathrm{X}_{22}$ & Poor detection of corrosion & $1.00 \mathrm{E}-03$ & & & \\
\hline
\end{tabular}


Table 3. Intermediate events and safety barriers of the BT in Fig. 5.

\begin{tabular}{llll}
\hline Symbol & Description & Symbol & Description \\
\hline $\mathrm{IE}_{1}$ & Human failure (unsafe behavior) & $\mathrm{IE}_{14}$ & Pipe shake \\
$\mathrm{IE}_{2}$ & Poor permit to work & $\mathrm{IE}_{15}$ & Equipment fatigue \\
$\mathrm{IE}_{3}$ & Failure of procedure implementation & $\mathrm{IE}_{16}$ & Heat fatigue \\
$\mathrm{IE}_{4}$ & Stress and hurry during work & $\mathrm{IE}_{17}$ & Gas temperature changes \\
$\mathrm{IE}_{5}$ & Process failure & $\mathrm{IE}_{18}$ & Mechanical fatigue \\
$\mathrm{IE}_{6}$ & Overpressure & $\mathrm{ESD}_{\mathrm{a}}$ & Automatic emergency shutdown \\
$\mathrm{IE}_{7}$ & Orifice obstruction/poor filtering & $\mathrm{ESD}_{\mathrm{m}}$ & Manual emergency shutdown \\
$\mathrm{IE}_{8}$ & Blockage of pipes & $\mathrm{II}$ & Immediate ignition \\
$\mathrm{IE}_{9}$ & Mechanical Failure & $\mathrm{DI}$ & Delayed ignition \\
$\mathrm{IE}_{10}$ & Lack of proper fastening & $\mathrm{Cong}$ & Congestion \\
$\mathrm{IE}_{11}$ & Corrosion & & \\
$\mathrm{IE}_{12}$ & External corrosion & & \\
$\mathrm{IE}_{13}$ & Internal corrosion & & \\
\hline
\end{tabular}


Table 4. Consequences of the regulator system failure.

\begin{aligned} & \hline Symbol Consequences \\ & \hline C1 Near miss \\ & C2 Moderate material loss \\ & C3 Flash fire, minor property damage \\ & C4 Vapor cloud explosion (VCE), minor propriety damage \\ & C5 Major material loss \\ & C6 Flash fire, major property damage, possibility of fatalities \\ & C7 Vapor cloud explosion (VCE), catastrophic property damage, high death toll \\ & C8 Jet fire, moderate property damage \\ & C9 Jet fire, catastrophic property damage, high death toll \\ & \hline\end{aligned}


Table 5. Failure probability of safety barriers in BT.

\begin{tabular}{lc}
\hline Safety barriers & Probability \\
\hline Immediate ignition barrier & 0.10 \\
Delay ignition barrier (when $\mathrm{ESD}_{\mathrm{m}}$ worked) & 0.30 \\
Delay ignition barrier (when $\mathrm{ESD}_{\mathrm{m}}$ failed) & 0.60 \\
Congestion & 0.60 \\
$\mathrm{ESD}_{\mathrm{a}}$ & 0.33 \\
$\mathrm{ESD}_{\mathrm{m}}$ & 0.33 \\
\hline
\end{tabular}


Table 6. probabilities results of $\mathrm{BT}$ and $\mathrm{BN}$.

\begin{tabular}{lccc}
\hline Critical event and consequences & $\begin{array}{c}\text { Prior probabilities } \\
(\mathrm{BT})\end{array}$ & $\begin{array}{c}\text { Prior probabilities } \\
(\mathrm{BN})\end{array}$ & $\begin{array}{c}\text { Updated } \\
\text { probability (BN) }\end{array}$ \\
\hline RSF & $7.47 \mathrm{E}-02$ & $7.11 \mathrm{E}-02$ & $1.00 \mathrm{E}+00$ \\
Process failures & $7.20 \mathrm{E}-03$ & $7.20 \mathrm{E}-03$ & $1.01 \mathrm{E}-01$ \\
Human failures (Unsafe behaviors) & $6.25 \mathrm{E}-02$ & $6.08 \mathrm{E}-02$ & $8.54 \mathrm{E}-01$ \\
Mechanical Failures & $5.00 \mathrm{E}-03$ & $3.90 \mathrm{E}-03$ & $5.44 \mathrm{E}-02$ \\
C1 & $5.00 \mathrm{E}-02$ & $4.77 \mathrm{E}-02$ & $6.70 \mathrm{E}-01$ \\
C2 & $1.04 \mathrm{E}-02$ & $9.90 \mathrm{E}-03$ & $1.40 \mathrm{E}-01$ \\
C3 & $1.80 \mathrm{E}-03$ & $1.70 \mathrm{E}-03$ & $2.39 \mathrm{E}-02$ \\
C4 & $2.70 \mathrm{E}-03$ & $2.60 \mathrm{E}-03$ & $3.58 \mathrm{E}-02$ \\
C5 & $2.90 \mathrm{E}-03$ & $2.80 \mathrm{E}-03$ & $3.92 \mathrm{E}-02$ \\
C6 & $1.80 \mathrm{E}-03$ & $1.70 \mathrm{E}-03$ & $2.35 \mathrm{E}-02$ \\
C7 & $2.60 \mathrm{E}-03$ & $2.50 \mathrm{E}-03$ & $3.53 \mathrm{E}-02$ \\
C8 & $1.70 \mathrm{E}-03$ & $1.60 \mathrm{E}-03$ & $2.21 \mathrm{E}-02$ \\
C9 & $8.00 \mathrm{E}-04$ & $8.00 \mathrm{E}-04$ & $1.09 \mathrm{E}-02$ \\
\hline
\end{tabular}




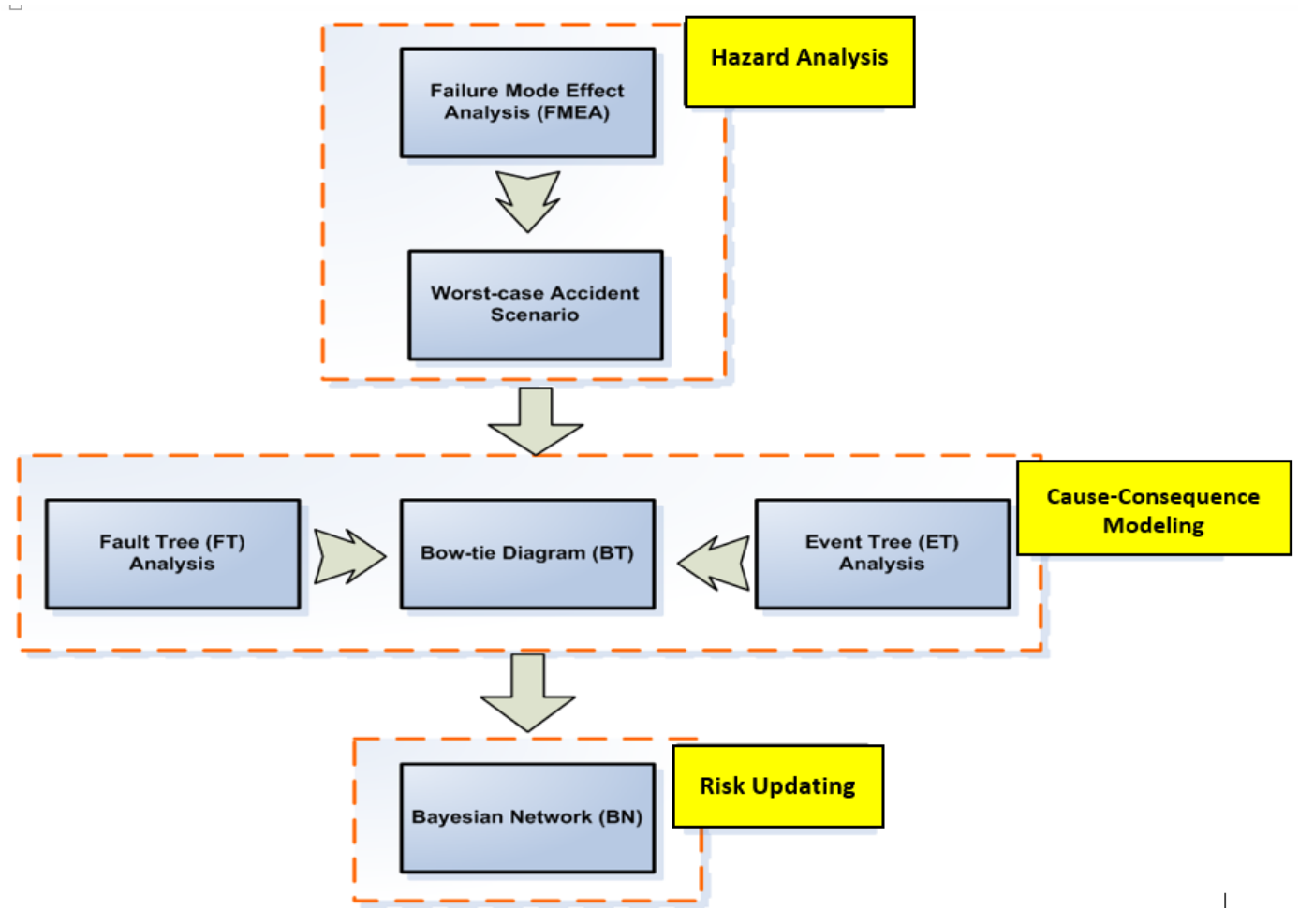

Fig. 1. Overview of the procedure used for DRA 


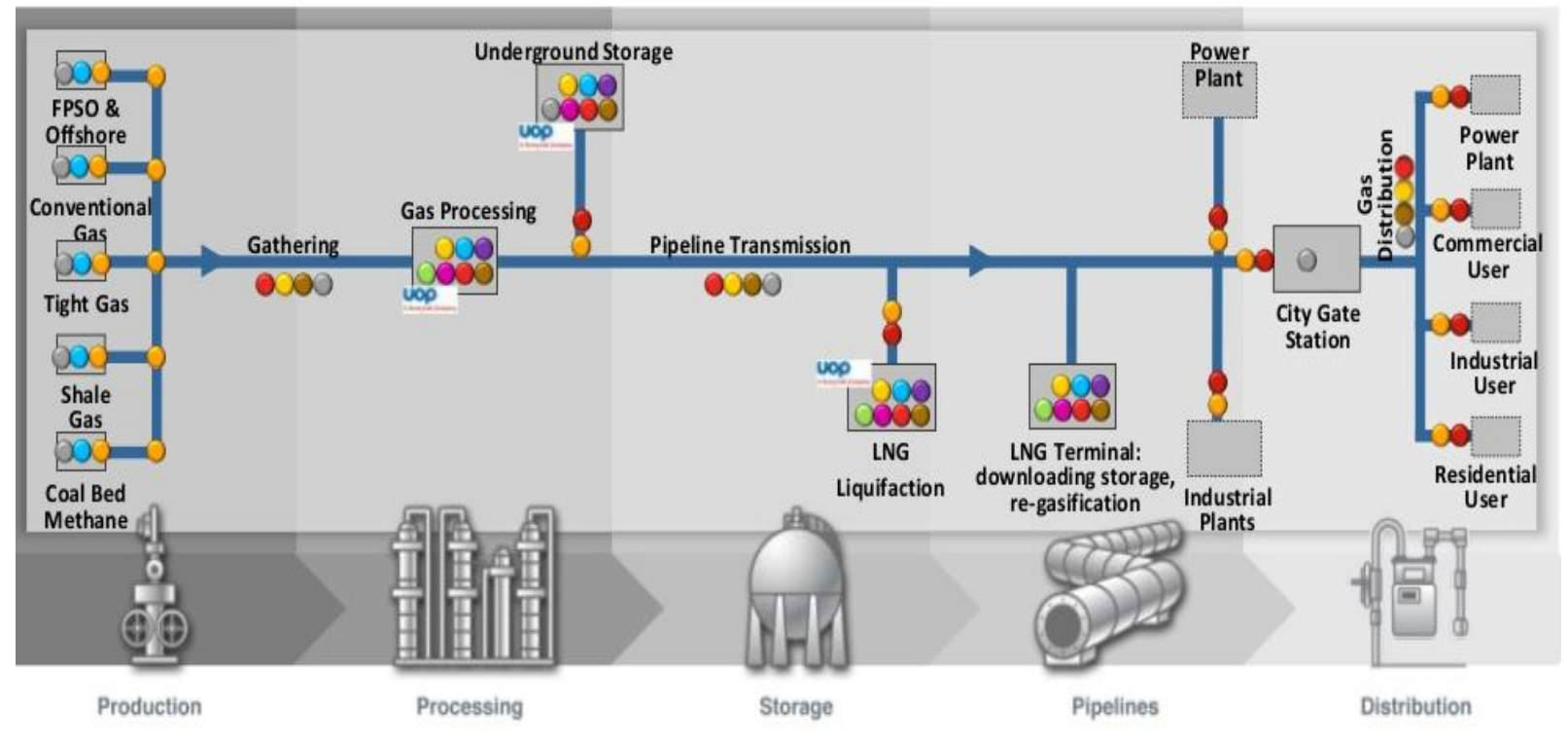

Fig. 2. Natural gas industry and CGS location

[Honeywell International, Inc: www.slideshare.net] 


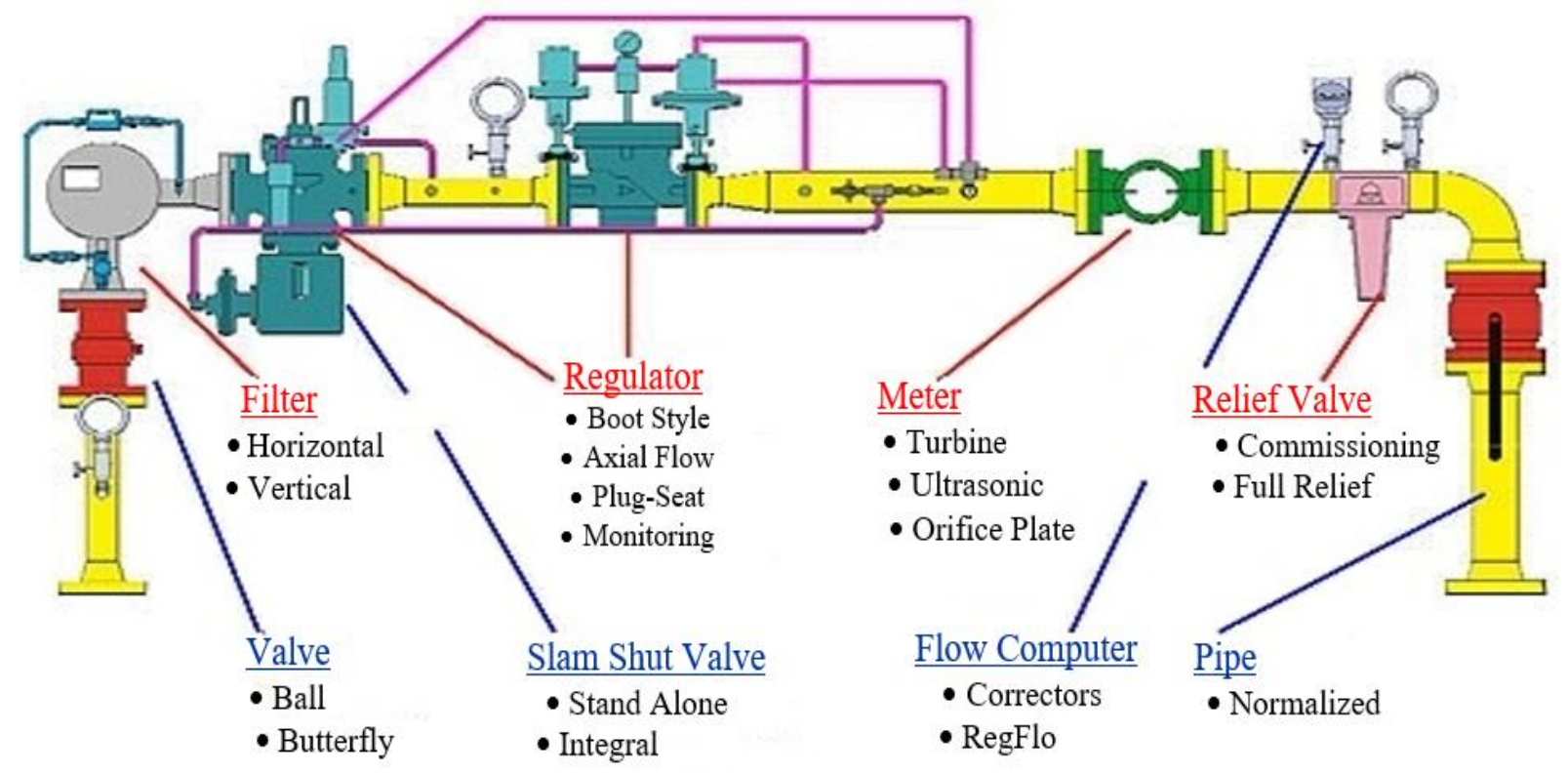

Fig.3. Main parts of each pipeline in a typical CGS

[http://www.icggroup.com/Pages/Gas-Pressure-Reducing-Stations.aspx] 


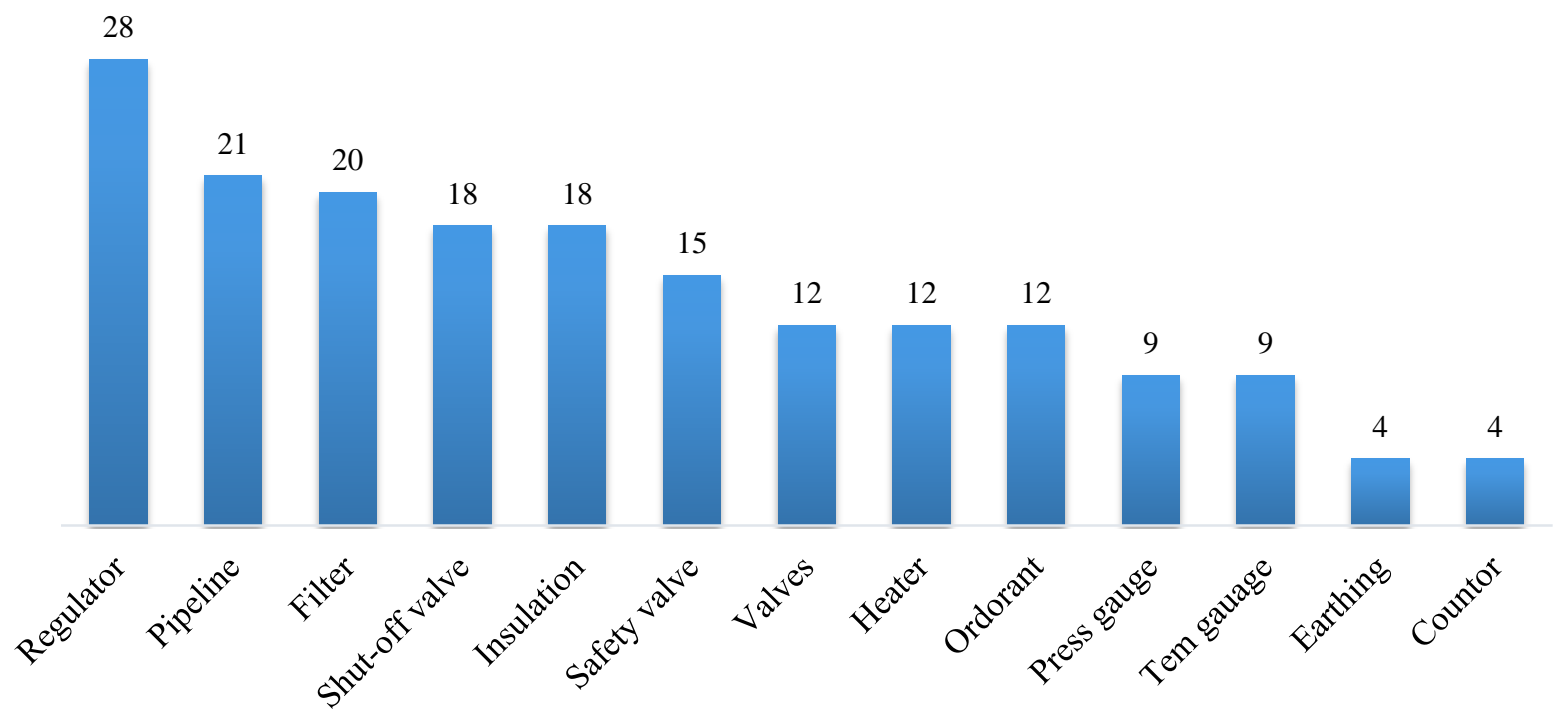

Fig.4. RPN of all hazard sources (hazardous subsystems) on CGS plants. 


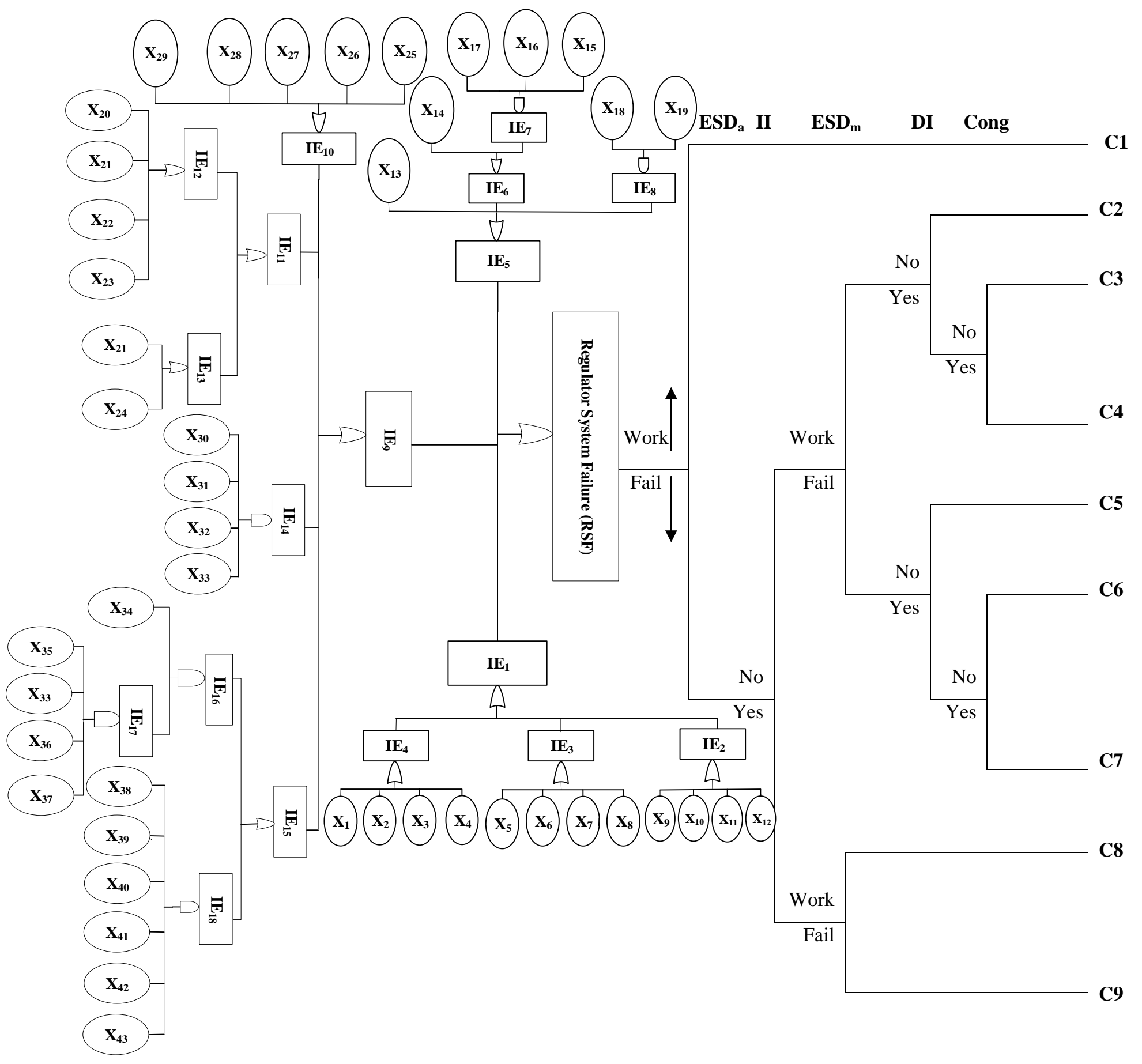

Fig. 5- Accident scenario modeling of regulator system failure using Bow-tie approach 


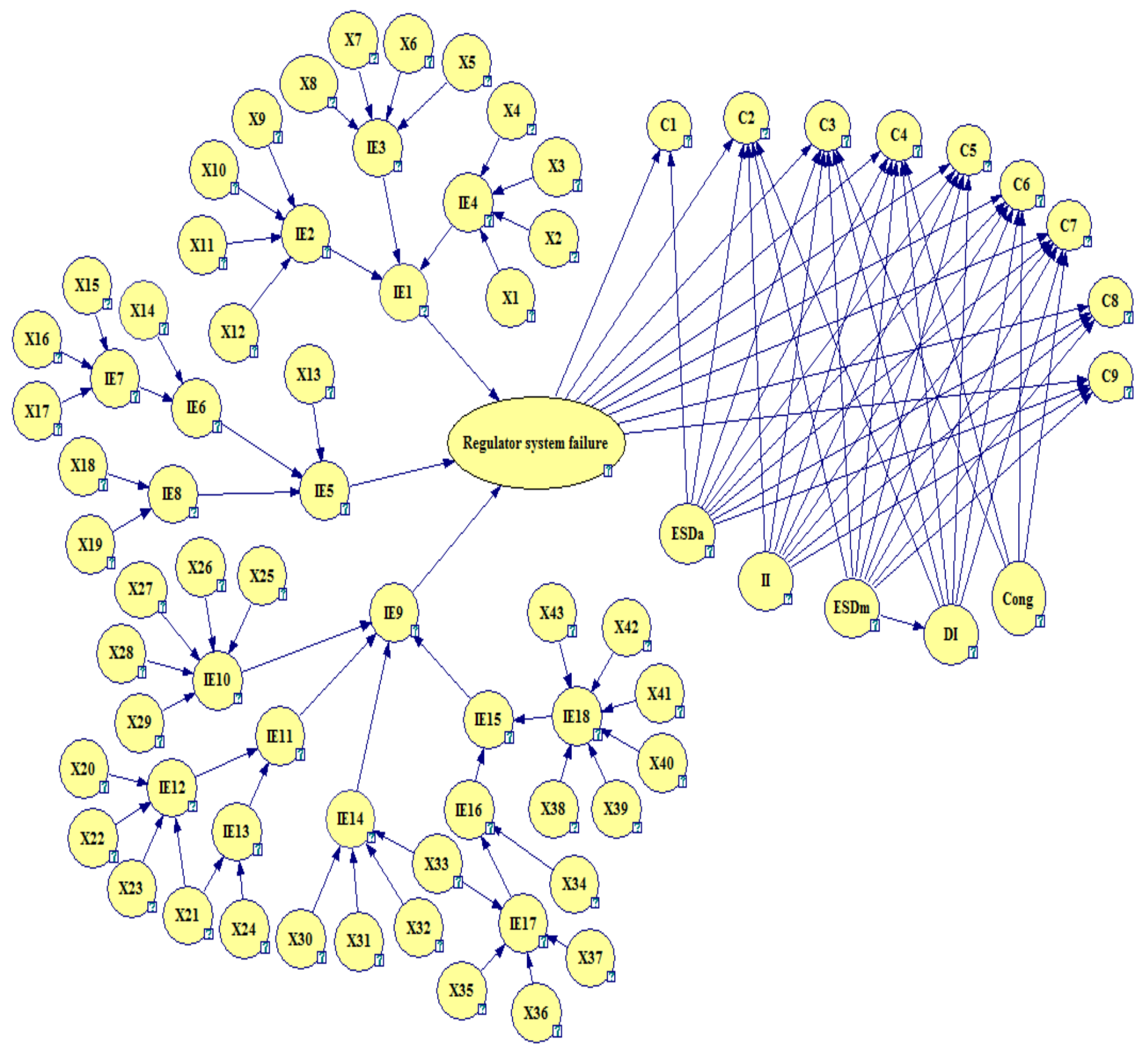

Fig. 6. Dynamic cause-consequence analysis of the regulator system failure using BN 


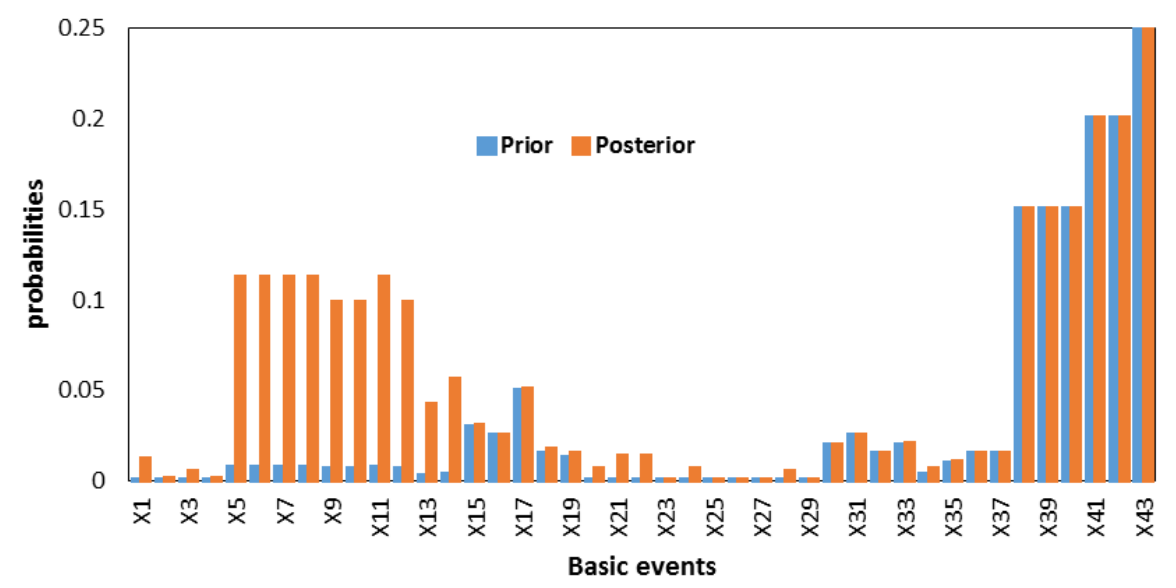

(a)

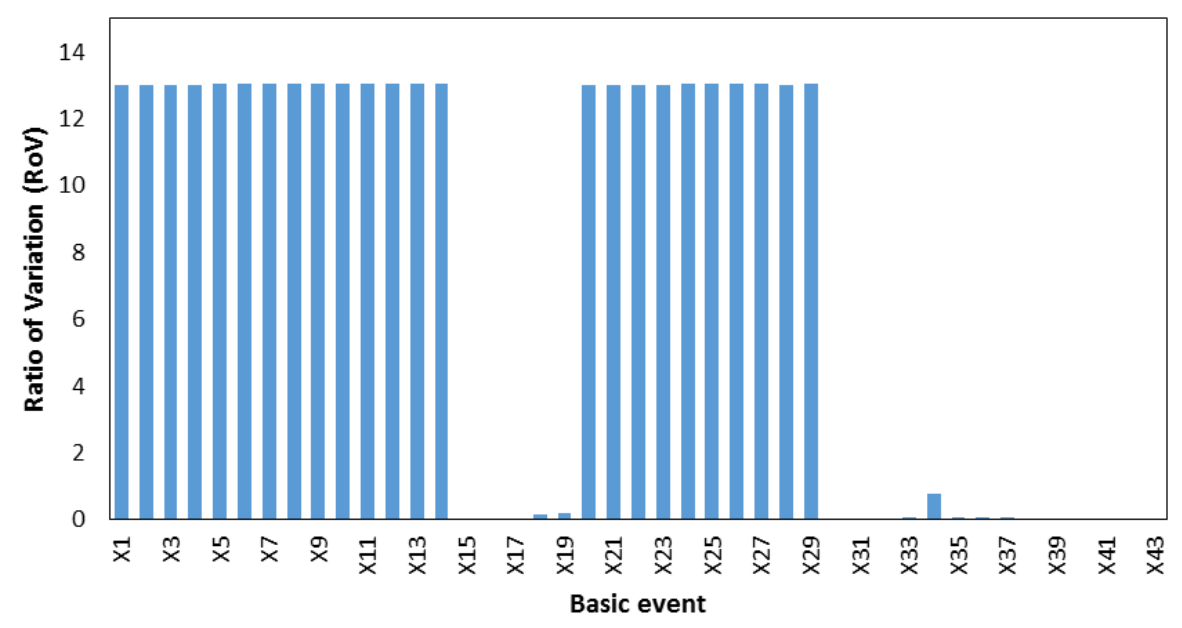

(b)

Fig 7. (a) Comparison of the prior and posterior (updated) probabilities of basic events. (b) Ratio of variation of the probabilities. 


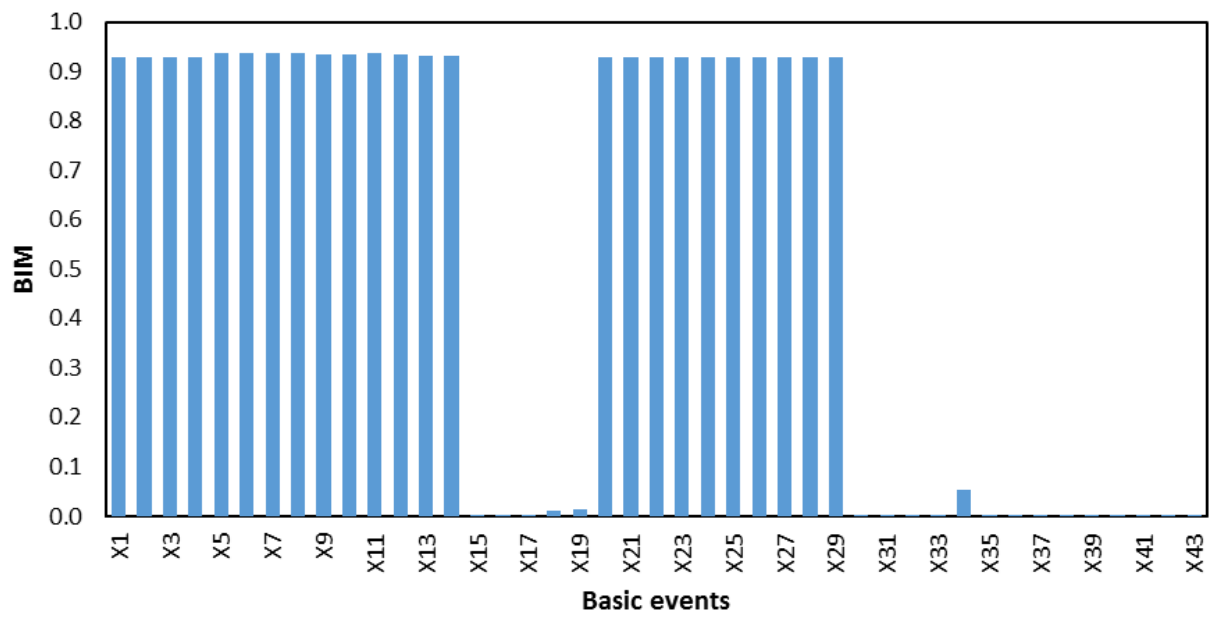

Fig. 8. BIM of the basic events. 


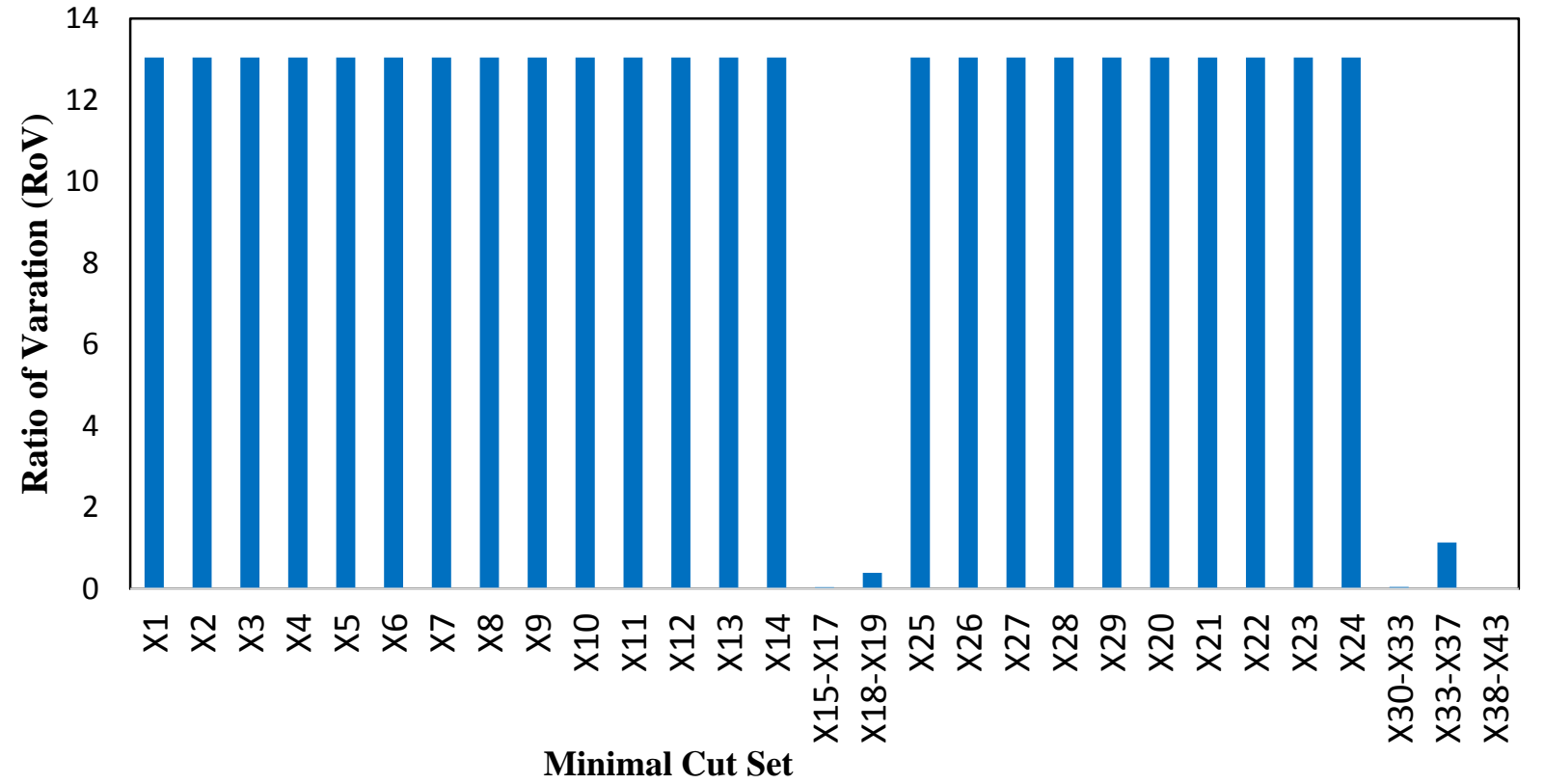

Fig 9. Ratio of variation for the MCSs of regulator systems failure. 


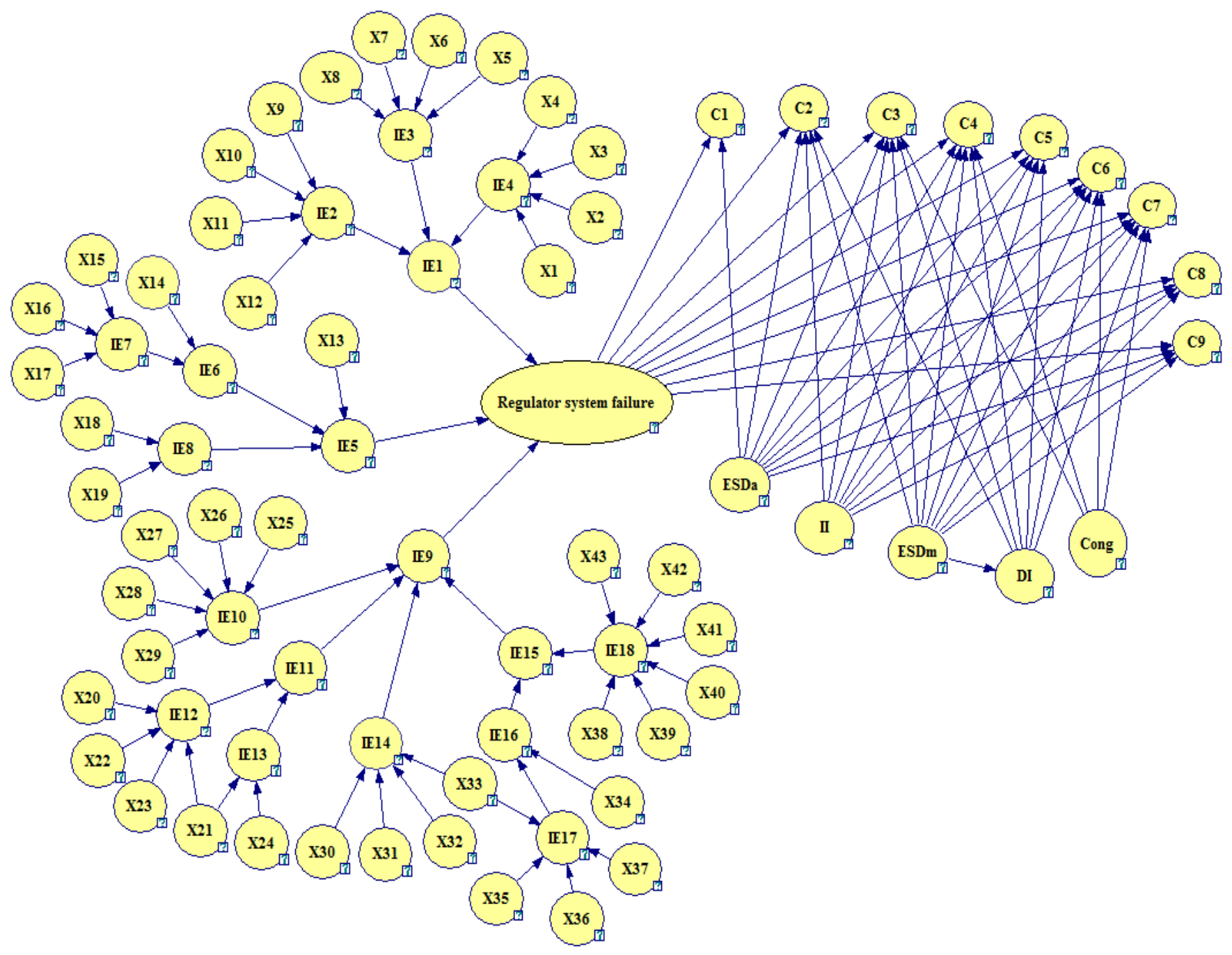

Fig. 6. Dynamic cause-consequence analysis of the regulator system failure using BN 